\title{
Highly Accelerated Aging Method for Poly(ethylene terephthalate) Film Using Xenon Lamp with Heating System
}

\author{
Masahiro Funabashi, ${ }^{1}$ Fumi Ninomiya, ${ }^{1}$ Akihiro Oishi, ${ }^{1}$ Akihiko Ouchi, ${ }^{2}$ \\ Hideaki Hagihara, ${ }^{1}$ Hiroyuki Suda, ${ }^{1}$ and Masao Kunioka ${ }^{1}$ \\ ${ }^{1}$ Research Institute for Sustainable Chemistry, National Institute of Advanced Industrial Science and Technology (AIST), \\ Higashi 1-1-1, Tsukuba, Ibaraki 305-8565, Japan \\ ${ }^{2}$ College of Science and Technology, Nihon University, 8-14 Kanda-Surugadai 1-Chome, Chiyoda-ku, Tokyo 101-8308, Japan
}

Correspondence should be addressed to Masahiro Funabashi; m.funabashi@aist.go.jp

Received 9 November 2015; Revised 11 March 2016; Accepted 31 March 2016

Academic Editor: Giancarlo Galli

Copyright ( 2016 Masahiro Funabashi et al. This is an open access article distributed under the Creative Commons Attribution License, which permits unrestricted use, distribution, and reproduction in any medium, provided the original work is properly cited.

\begin{abstract}
PET films were degraded at temperature higher than $100^{\circ} \mathrm{C}$ with steam and xenon light by using the newly developed system. Degradation products obtained using the proposed and conventional systems were essentially the same, as indicated by the similar increase in the intensity of the carbonyl peak near $1685 \mathrm{~cm}^{-1}$ in the FT-IR spectra of irradiated specimens and spectrum of original PET film. Elastic moduli derived from the stress-strain (SS) curves obtained in tensile tests were almost the same in the case of the proposed and conventional systems and were independent of the heating temperature, light intensity, and irradiation time. Tensile strength of degraded PET films decreases with increasing heating temperature. Tensile strengths of PET films degraded at same temperature decrease linearly with increasing intensity of xenon light. The lifetime at $90 \%$ strength of PET films was calculated. Attempts were made to express this lifetime as functions of the light intensity and the reciprocal of the absolute temperature by using the Eyring model. Estimated lifetime $15.9 \mathrm{~h}$ of tensile test using Eyring model for PET film agreed with the lifetime $22.7 \mathrm{~h}$ derived from data measured using the xenon weather meter.
\end{abstract}

\section{Introduction}

Poly(ethylene terephthalate) (PET) films are highly functional films having good mechanical properties such as flexibility and transparency; they are used as backsheets in solar batteries $[1,2]$ and as transparent flexible electrodes in smartphones and liquid crystal displays [3-5].

The polymer materials in these films are degraded by depolymerization, random chain scission, and oxidation due to environmental stress factors such as heat, chemicals, sunlight, or torsion. Functional products containing degraded polymer parts may undergo damage because of peeling or electrical breakdown.

Accelerated aging methods that reduce the time for estimating the lifetime of products are necessary to assess the durability of polymer materials. Table 1 presents examples of accelerated aging methods for durability evaluation, as defined by the International Organization for Standardization (ISO). These ISO test methods utilize laboratory lamps to simulate external environments under sunlight (weathering), as detailed in the ISO 4665 and 4892 procedures. The ISO 2578 and 11346 methods include ISO accelerated aging techniques that employ a shorter evaluation time than the real lifetime at temperatures higher than those encountered under actual conditions of use. These methods are based on the Arrhenius relationship between lifetime and temperature. Lifetime is related to a gradual decrease in a specified property of the polymer. Lifetime can be estimated by extrapolating the value at higher temperature to the actual temperature of use, based on the linear relationship between the logarithm of the lifetime and the reciprocal of the measured or estimated absolute temperature. Higher 
TABLE 1: International standards for evaluation of durability of plastic or rubber products.

\begin{tabular}{llcl}
\hline No. & Title & Accelerated stress & Note \\
\hline ISO 2578 & $\begin{array}{l}\text { Plastics: determination of time-temperature limits } \\
\text { after prolonged exposure to heat }\end{array}$ & Heat & Arrhenius plot \\
& $\begin{array}{l}\text { Plastics: methods of exposure to laboratory light } \\
\text { sources } \\
\text { Part 1: general guidance } \\
\text { ISO 4892 }\end{array}$ & Lart 2: xenon-arc lamps & Weathering \\
& $\begin{array}{l}\text { Part 3: fluorescent UV lamps } \\
\text { Part 4: open-flame carbon-arc lamps }\end{array}$ & Durability \\
\hline ISO 3384 & $\begin{array}{l}\text { Rubber, vulcanized or thermoplastic: } \\
\text { determination of stress relaxation in compression } \\
\text { Part 1: testing at constant temperature } \\
\text { Part 2: testing with temperature cycling }\end{array}$ & Mechanical stress & \\
\hline ISO 4665 & $\begin{array}{l}\text { Rubber, vulcanized, or thermoplastic: resistance } \\
\text { to weathering }\end{array}$ & Light \\
\hline ISO 11364 & $\begin{array}{l}\text { Rubber, vulcanized or thermoplastic: estimation } \\
\text { of lifetime and maximum temperature of use }\end{array}$ & Heat \\
\hline $\begin{array}{l}\text { Imaging materials, compact discs (CD-ROM): } \\
\text { method for estimating the life expectancy based } \\
\text { on the effects of temperature and relative humidity }\end{array}$ & $\begin{array}{l}\text { Highly accelerated temperature and humid system } \\
\text { test }\end{array}$ & Heat, humidity \\
\hline IEC & Heat, humidity & Arrhenius plot \\
\hline
\end{tabular}

temperature is effective for acceleration of weathering test. Testing condition at temperature higher than $100^{\circ} \mathrm{C}$ is dry without water. Therefore, testing temperatures of all of the ISO standards on durability in Table 1 are less than $100^{\circ} \mathrm{C}$. The International Electrotechnical Commission (IEC) has one of the standards for evaluation of reliability of electric device, IEC 60068-2-66. Some of test temperatures in IEC 60068-266 are higher than $100^{\circ} \mathrm{C}$ with $85 \% \mathrm{RH}$ using pressure vessel. The accelerated methods of published standards expressed in Table 2 are effective for evaluation of actual products. Numbers of measurements are required for materials under development. Therefore, more accelerated aging methods are required for these materials in order to reduce the developing period.

Estimation of the lifespan of electronic products is important in terms of reliability. The durability of the polymer materials in these products can be estimated based on the polymer lifetime. For estimation of durability, the period during which the polymer properties degrade below the desired level should be determined under actual conditions of use, such as room temperature and normal humidity. These measured data can be used to determine the real lifetime of polymer materials. However, the durability of products with a longer lifetime, which is assumed to be over 5 years, cannot be confirmed using real lifetime data. The durability of PET films has been evaluated based on thermal degradation $[6,7]$, hydrolytic degradation [8], and chemical reactions induced by laboratory light [9-16]. Testing temperatures of all of these studies are lower than $100^{\circ} \mathrm{C}$. Previously, we evaluated the mechanisms of PET film degradation in detail by using a weathering test machine; we analyzed
TABLE 2: Test conditions and number of specimens.

\begin{tabular}{|c|c|c|c|}
\hline $\begin{array}{l}\text { Irradiation time } \\
\mathrm{h}\end{array}$ & $\begin{array}{c}\text { Intensity } \\
\mathrm{W} / \mathrm{m}^{2}\end{array}$ & $\begin{array}{c}\text { Temperature } \\
{ }^{\circ} \mathrm{C} \\
\end{array}$ & Number of specimens \\
\hline 0 & 0 & RT & 5 \\
\hline 20 & 231.3 & 47.1 & 5 \\
\hline 8 & 249.9 & 85 & 5 \\
\hline 8 & 225.5 & 89 & 5 \\
\hline 8 & 228.8 & 104 & 4 \\
\hline 8 & 221.5 & 128 & 4 \\
\hline 8 & 221.6 & 156 & 4 \\
\hline 8 & 220.9 & 180 & 3 \\
\hline 8 & 217.5 & 150 & 6 \\
\hline 8 & 220.3 & 150 & 5 \\
\hline 8 & 166.1 & 150 & 4 \\
\hline 8 & 111.0 & 150 & 5 \\
\hline 8 & 55.4 & 150 & 4 \\
\hline 8 & 0 & 150 & 6 \\
\hline 8 & 222.1 & 150 & 5 \\
\hline 6 & 222.1 & 150 & 5 \\
\hline 4 & 222.1 & 150 & 6 \\
\hline 2 & 222.1 & 150 & 6 \\
\hline 8 & 0 & 80 & 6 \\
\hline 8 & 222.1 & 80 & 6 \\
\hline 8 & 167.0 & 80 & 6 \\
\hline 8 & 111.4 & 80 & 6 \\
\hline 8 & 55.6 & 80 & 6 \\
\hline
\end{tabular}


the molecular structure in the crystalline or amorphous regions by thermal-mechanical methods such as a differential scanning calorimetry (DSC), dynamic mechanical analysis (DMA), and positron annihilation spectroscopy (PALS) [17].

Recently, durable carbon fiber reinforced plastics (CFRP) with epoxide resin have been developed for products with longer lifetime (10 to 20 years) [18]. Highly accelerated aging methods are required for these durable polymers, which cannot be degraded using conventional accelerated aging techniques. In addition, for polymer materials used as sealing materials in power electronic devices, the use of temperatures exceeding $200^{\circ} \mathrm{C}$ is required to induce accelerated aging. In these cases, there is limited acceleration of aging when the temperature of use is changed to the degradation or melting temperature. Accordingly, alternative stronger stress factors such as strong light or higher humidity at high temperatures are applied to the evaluated materials for further accelerated aging. For example, one accelerated aging method employs multiple stresses such as heat and humidity for compact discs (CD), based on the ISO 18921 method (Table 1). The lifetime at 5 measurement points such as $85^{\circ} \mathrm{C} / 80 \% \mathrm{RH}$ (relative humidity), $85^{\circ} \mathrm{C} / 70 \% \mathrm{RH}, 85^{\circ} \mathrm{C} / 60 \% \mathrm{RH}, 75^{\circ} \mathrm{C} / 80 \% \mathrm{RH}$, and $65^{\circ} \mathrm{C} / 80 \% \mathrm{RH}$ can be used to estimate the lifetime over 100 years at $25^{\circ} \mathrm{C} / 50 \% \mathrm{RH}$ (which is the condition of use for CDs) based on the Eyring model, as described in the ISO 18921 method. A modified ISO method, in which 4 accelerated aging points are measured based on heat and humidity, gave more accurate lifetime for CDs [19]. Accelerated aging methods based on heat and pressure application for heat-resistant fiber reinforced plastic (FRP) materials in hot water have been developed; these methods can be used for estimating lifetime of more than 10 years [20]. For accelerated aging using a short evaluation time, it is important to accelerate degradation of the products using more than one type of stress factor (such as heat, humidity, pressure, or light). Degradation of plastic products by light can be evaluated by many ISO methods, as indicated in Table 1. It is thought that the aging at temperature higher than $100^{\circ} \mathrm{C}$ with light and water is effective for accurate lifetime prediction of polymer products. A xenon lamp is selected among the light sources of ISO 4892 in Table 1, since a spectral distribution curve of the xenon lamp agrees well with that of sunlight. Light intensity from 300 to $400 \mathrm{~nm}$ for the average sunlight at the ground surface is $60 \mathrm{~W} / \mathrm{m}^{2}$. The durability of the polymer materials under sunlight was evaluated using the xenon weather meters with light intensity from 300 to $400 \mathrm{~nm} 60 \mathrm{~W} / \mathrm{m}^{2}$ at temperature less than $100^{\circ} \mathrm{C}$ according to ISO 4892 Part 2 [21-23]. Although the light intensity from 300 to $400 \mathrm{~nm}$ can be controlled as $180 \mathrm{~W} / \mathrm{m}^{2}$ for some of the xenon weather meters of manufacturers, the test temperatures with the light intensity of $180 \mathrm{~W} / \mathrm{m}^{2}$ for those weather meters are less than $100^{\circ} \mathrm{C}$.

In this paper, a highly accelerated aging method using light generated by a xenon lamp and heat for evaluation of the durability of PET film is described. We proposed the new system in which the accelerated weathering tests can be performed at temperature higher than $100^{\circ} \mathrm{C}$ with steam and xenon light. The time required reaching $90 \%$ of the initial strength for PET films degraded by light and heat with water is evaluated for lifetime analysis. The Eyring model is applied to predict the lifetime when the strength declines to $90 \%$ of the original value.

\section{Experimental}

2.1. PET Film. Poly(ethylene terephthalate) (PET) film $\left(50 \mu \mathrm{m}\right.$; Lumirror ${ }^{\circledR}$ S10, Toray Industries, Inc., Japan; $M_{n}=$ 7,500 based on HFIP GPC, $T_{m}=258^{\circ} \mathrm{C}$, and crystallinity $=$ $24 \%$ from DSC) was used. Dumbbell shaped (type V, parallel part; $5 \times 25 \mathrm{~mm}$ ) specimens were prepared along the machine direction (MD) for the accelerated aging test using light and temperature. It was confirmed that no ultraviolet absorber was present inside the PET film based on the detection of no specific absorbance over $320 \mathrm{~nm}$ from UV measurement.

2.2. Accelerated Aging Apparatus. Accelerated aging of the PET film was measured using a xenon lamp irradiation system. Details of this system are shown in Figure 1. A front view of the chamber and a cross-sectional side view of the system are shown in Figure 1. Photolysis was conducted with a $500 \mathrm{~W}$ xenon lamp (USHIO Optical Modulex SX-UI500XQ) fitted with an $18 \mathrm{~cm}$ water filter. The water filter was used to minimize IR radiation. The stainless steel chamber was covered with quartz glass $(3 \mathrm{~mm})$ up to the lamp. The stainless steel chamber was constructed using stainless steel plate $(10 \times$ $200 \times 200 \mathrm{~mm})$ and a stainless steel frame $(25 \times 200 \times$ $200 \mathrm{~mm}$, with a hole of $150 \times 150 \mathrm{~mm}$ ). The stainless chamber can be heated by means of a rubber heater on the backside of the stainless steel plate. The irradiated area was circular with a diameter of around $10 \mathrm{~cm}$. The inside temperature was controlled from 47 to $180^{\circ} \mathrm{C}$ using a chromel-alumel (CA) thermocouple placed on the film surface outside of the light spot and a rubber sheet heater, since the temperature measured by thermocouple placed inner of the light spot is higher than that placed outside of the light spot.

Ordinary polymer products are degraded by light with a wavelength shorter than $400 \mathrm{~nm}$ because additives of polymer products and polymers themselves absorb light at wavelengths below $400 \mathrm{~nm}$. Materials with various functional groups are produced from the PET films during the photodegradation process, and the degraded PET film absorbs light with a wavelength of $350 \mathrm{~nm}$ due to these products, although the original PET film does not absorb light with a wavelength greater than $320 \mathrm{~nm}$. This additional absorption accelerates photodegradation of the PET film [14]. Most of the ultraviolet (UV) light with a wavelength of less than $320 \mathrm{~nm}$ in sunlight cannot reach the earth's surface. Therefore, UV light with a wavelength of less than $300 \mathrm{~nm}$ was blocked by using a filter in the ordinary weathering test meter. A UV275 filter was employed for the weathering test meter used in this study. The UV275 filter reduces the light intensity by half for wavelengths around $275 \mathrm{~nm}$ and completely blocks light with wavelengths less than $275 \mathrm{~nm}$. The light intensity is reduced by about $10 \%$ due to reflection on the surface of the filter. UV light with a wavelength of 300 to $400 \mathrm{~nm}$ is effective for accelerated degradation. No filter was employed for the xenon lamp system in this study since greater acceleration of aging 


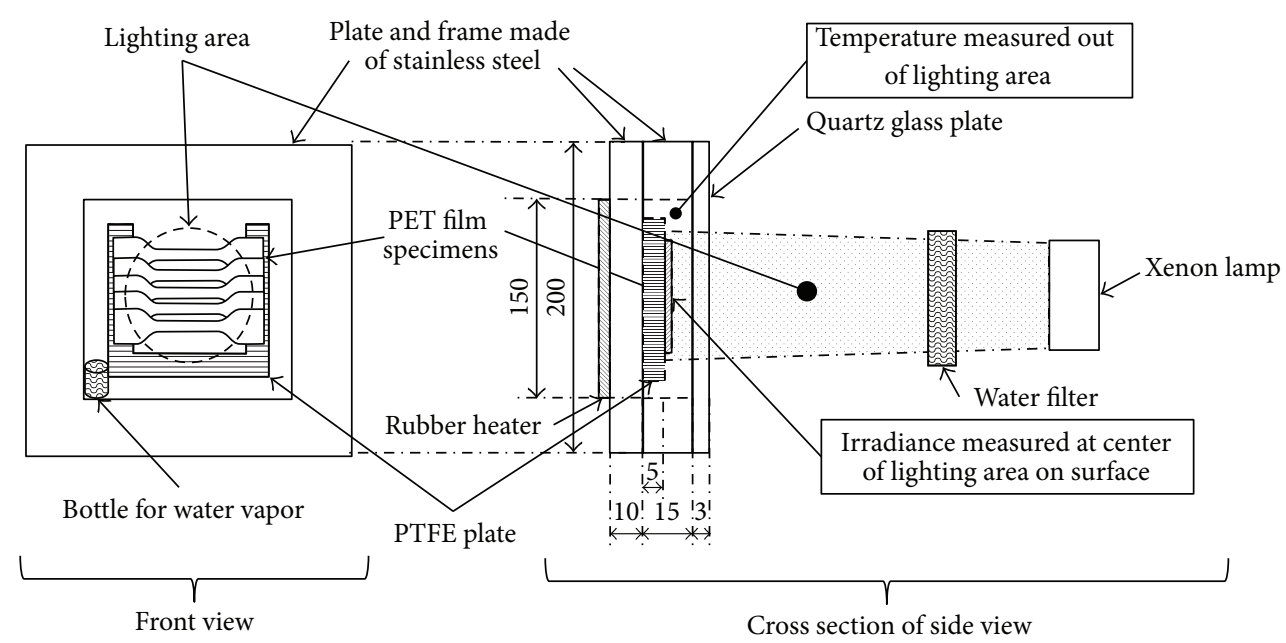

FIGURE 1: Irradiation system using a xenon lamp with temperature control (units are mm).

by the xenon weather meter can be expected by using the xenon lamp system without any filter.

2.3. Light Intensity of Xenon Lamp. The light intensity from the xenon lamp reaching the sample surface was measured using a Radiometer RAX34C (Suga Test Instruments Co., Ltd., Japan), which can measure light intensity from 300 to $400 \mathrm{~nm}$. The light intensity of the xenon lamp ranged from 60 to $240 \mathrm{~W} / \mathrm{m}^{2}$. The light intensity was measured without the quartz glass and that through the quartz glass plate was estimated by multiplying this data piece by a factor of 0.924 to estimate the light intensity without the quartz glass. The value of 0.924 was derived from the data measured around $200 \mathrm{~W} / \mathrm{m}^{2}$ without the quartz glass and that through the quartz glass. A deep discussion of the effect of the filter is necessary in order to probe the detailed mechanism of photodegradation. The necessity of the filter and the effect of the filter are a topic for further study.

2.4. Humidity in a Chamber. Deionized water $(1 \mathrm{~mL})$ was added to the bottle inside the chamber every 2 hours to maintain the water vapor in order to supply water in the chamber. The pressure of vapored water, that is, steam, at $100^{\circ} \mathrm{C}$ is almost $1 \mathrm{~atm}$ and the pressure of steam increases with increasing temperature. The pressure of steam at $120^{\circ} \mathrm{C}$ is around $2 \mathrm{~atm}$. When the water is added, the bottle is not dry. Therefore, it is thought that the humidity in the chamber is almost $100 \% \mathrm{RH}$ at temperature lower than $100^{\circ} \mathrm{C}$ and gas in the chamber at temperature higher than $100^{\circ} \mathrm{C}$ is almost steam. Humidity in the chamber is not measured, since the ordinal humidity meter cannot be used at temperature higher than $100^{\circ} \mathrm{C}$. Dumbbell shaped specimens were suspended in midair by using plastic tape affixed to a PTFE plate inside the chamber, as indicated in Figure 1. Test conditions and number of specimens are shown in Table 2.

2.5. Mechanical Properties. Tensile tests according to ISO 527-3 were performed on the PET films at room temperature
(RT) using a Shimadzu Autograph AG-1000B instrument. The grip distance was $50 \mathrm{~mm}$ and the gage length was $25 \mathrm{~mm}$. The test speed was $2 \mathrm{~mm} \mathrm{~min}^{-1}$. The dumbbell shape of specimens in this paper is defined as a type 5 specimen in ISO 527-3. Tensile strength is defined as the maximum stress derived from the stress and strain (SS) curves. The elastic modulus $(E)$ is defined as the gradient of the linear part of the SS curve from the tensile test. These values were determined as the average of 3-6 measurements, where numbers of measurements are shown in Table 2.

2.6. Infrared Spectra. The infrared (IR) absorbance spectra of the PET film specimens were measured using a Thermo Scientific Nicolet 6700 FT-IR using a resolution of $4 \mathrm{~cm}^{-1}$ by 24 scans. A transmission spectrum for each specimen (irradiated under various conditions) was derived from the FT-IR absorbance curve.

\section{Results and Discussion}

3.1. Transmission Spectra from FT-IR. The FT-IR transmission spectrum of the PET film specimen degraded using the xenon weather meter was compared with that of PET film degraded using the newly developed xenon lamp system, as shown in Figure 1. Specimens were irradiated with $180 \mathrm{~W} / \mathrm{m}^{2}$ with a black panel temperature of $63^{\circ} \mathrm{C}$ for $192 \mathrm{~h}$ using the xenon weather meter, with $166 \mathrm{~W} / \mathrm{m}^{2}$ at $150^{\circ} \mathrm{C}$ for $8 \mathrm{~h}$ using the xenon lamp system, or with $222 \mathrm{~W} / \mathrm{m}^{2}$ at $150^{\circ} \mathrm{C}$ for $6 \mathrm{~h}$ using the xenon lamp system. A black panel temperature of $63^{\circ} \mathrm{C}$ corresponds to a temperature of $30.4^{\circ} \mathrm{C}$ inside the weather meter. The tensile strengths of these samples were 23.6, 52.6, and 68.6 MPa, respectively. Transmission spectra of these specimens and the unirradiated specimen are shown in Figure 2. The enlarged spectra near $1700 \mathrm{~cm}^{-1}$ are shown in the figure. The IR spectrum of the irradiated specimens showed an increase in the intensity of the carbonyl peak near $1700 \mathrm{~cm}^{-1}$. The intensity of the shoulder carbonyl peaks around $1685 \mathrm{~cm}^{-1}$ increased for the samples irradiated using 


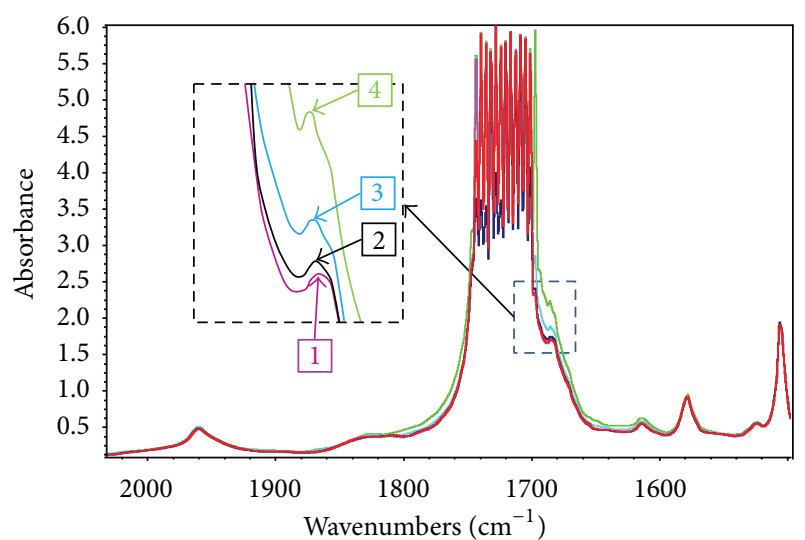

FIGURE 2: FT-IR transmission spectra of PET film specimens. 1: original PET film, 2: $180 \mathrm{~W} / \mathrm{m}^{2}$ at $32^{\circ} \mathrm{C}$ for $192 \mathrm{~h}$ by weathering test meter, $3: 166 \mathrm{~W} / \mathrm{m}^{2}$ at $150^{\circ} \mathrm{C}$ for $8 \mathrm{~h}$ by new system, and $4: 222 \mathrm{~W} / \mathrm{m}^{2}$ at $150^{\circ} \mathrm{C}$ for $6 \mathrm{~h}$ by new system.

the weather meter and the xenon weather meter compared with those of the original unirradiated PET film. These results indicate that the chemical product of degradation of the PET film irradiated with the xenon weather meter may be similar to that of the PET film irradiated using the xenon lamp with heating. Degradation of PET by the xenon weather meter can be accelerated by increasing the light intensity, irradiation time, or heating temperature of the xenon lamp system.

The pressure of vapored water, that is, steam, at $100^{\circ} \mathrm{C}$ is almost $1 \mathrm{~atm}$ and the pressure of steam increases with increasing temperature. The pressure of steam at $150^{\circ} \mathrm{C}$ is $4.76 \mathrm{~atm}$. Circumstance of specimens in the new system at $150^{\circ} \mathrm{C}$ is almost steam. Ration of oxygen in circumstance of specimen at $150^{\circ} \mathrm{C}$ is smaller than that at $63^{\circ} \mathrm{C}$ in the xenon weather meter. This causes the difference of the intensity of shoulder carbonyl peak of specimen degraded in the weather meter and that in the new system. It is necessary for accurate evaluation of degradations of PET film by hydrolytic degradation and oxidative degradation to control steam content in the system. This will be further topic.

3.2. Stress-Strain (SS) Curves from Tensile Tests. SS curves were obtained from tensile tests of the specimens irradiated at various temperatures. The light intensity on the surface of the specimens was estimated to be 222 or $231 \mathrm{~W} / \mathrm{m}^{2}$, as shown in Figure 1. Representative SS curves for the specimens irradiated at each temperature are shown in Figure 3. The SS curves obtained under the various conditions are almost the same. The yield points of the SS curves of the unirradiated specimen and the specimens irradiated at $47^{\circ} \mathrm{C}$ were not clearly defined. Necking of the specimens started just after the elastic area without yielding. The SS curves of the specimens irradiated at 89 and $104^{\circ} \mathrm{C}$ had a clear yield point. This fact indicates that irradiation induced a slight structural change in the crystallinity of PET. Excluding the near yield points, the SS curves of all of the specimens irradiated at different temperatures are superimposable on the SS curve of the unirradiated specimen. This means that irradiation using

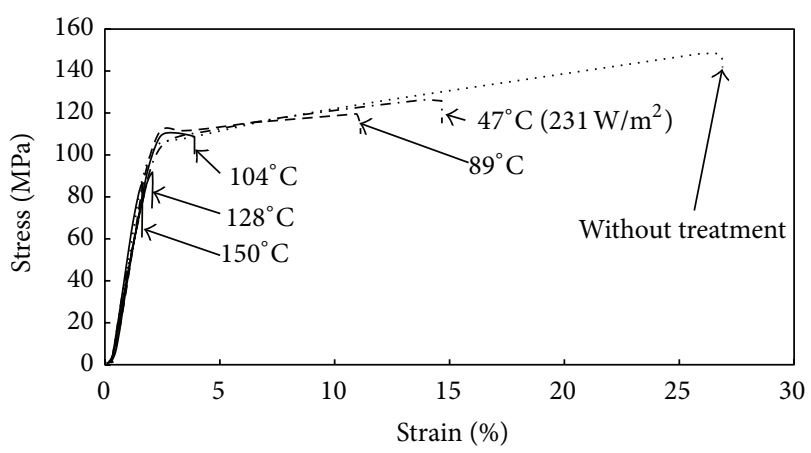

FIGURE 3: Stress-strain curves of tensile tests of specimens with light intensity around $222 \mathrm{~W} / \mathrm{m}^{2}$ at various temperatures.

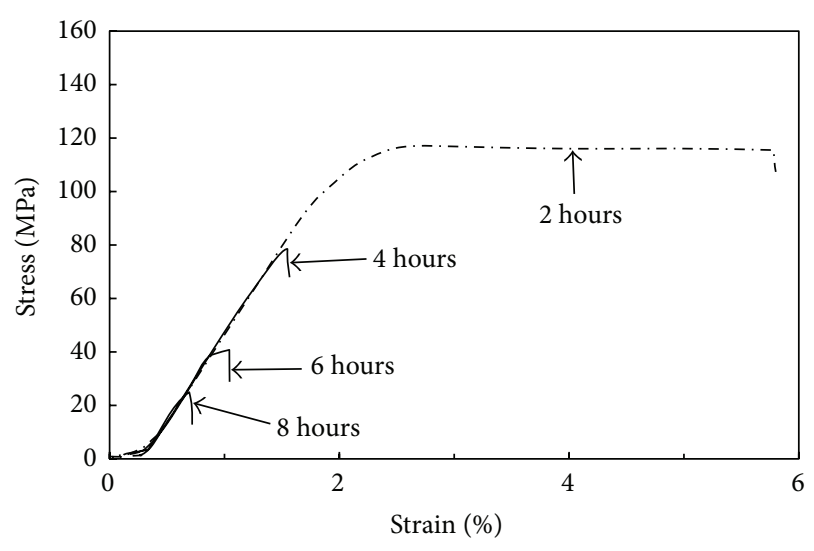

FIGURE 4: Stress-strain curves for tensile tests of specimens with light intensity $222 \mathrm{~W} / \mathrm{m}^{2}$ at chamber temperature $150^{\circ} \mathrm{C}$.

the xenon lamp induced degradation of the PET film within a narrow area, and the overall structure (as indicated by the elastic modulus and elastic limit) was not damaged. This behavior can be explained in terms of the chain model; that is, some of the chains are damaged by light from the xenon lamp, and the chain-damaged maximum is broken by the tensile test. The profile of the SS curve before the break is the same as that of the unirradiated specimen because the mechanical properties such as the elastic modulus, elastic limit, plastic behavior, and strength are maintained by the remaining undamaged chains.

The SS curves from tensile tests of the specimens degraded with light intensity of $222 \mathrm{~W} / \mathrm{m}^{2}$ at $150^{\circ} \mathrm{C}$ are shown in Figure 4. All of the SS curves are superimposable on the SS curve of the specimen irradiated for $2 \mathrm{~h}$. This result can be explained on the same basis as the results presented in Figure 3 . That is, the specimens were damaged by xenon light in a very narrow area, and the damaged area increased with increasing irradiation time; consequently, the tensile strength decreased with increasing irradiation time. However, the global properties (such as elastic modulus, elastic limit, and yield point) did not vary until $8 \mathrm{~h}$ of irradiation.

3.3. Strength and Elastic Modulus. Strengths and elastic moduli of the PET films were derived from the SS curves obtained 


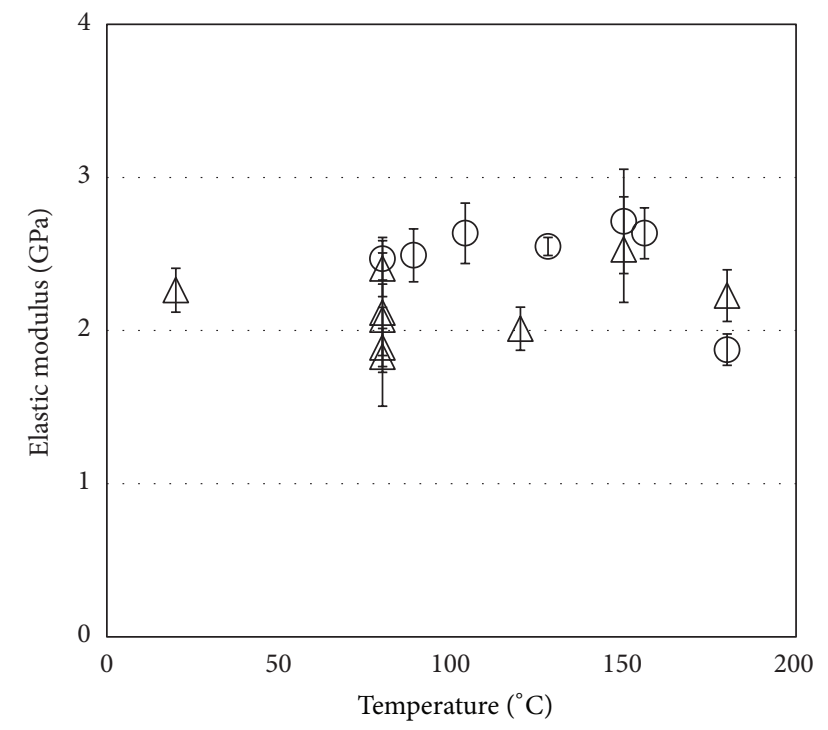

Figure 5: Relationship between elastic modulus and temperature: $\bigcirc$ light intensity $222 \mathrm{~W} / \mathrm{m}^{2}$ for 8 hours; $\triangle$ heating only without irradiation for 8 hours.

from tensile tests, as described in Section 2. The relationship between these parameters and temperature for specimens irradiated with $222 \mathrm{~W} / \mathrm{m}^{2}$ are shown in Figures 5 and 6. Figure 5 shows the relationship between the temperature and elastic modulus. The elastic moduli in Figure 5 are almost the same, independent of the temperature and xenon light irradiation. Some specimens were broken below the yield point or elastic limit, as shown in Figure 5. When the yield point and elastic limit could be derived from the SS curves for all of the specimens, these values were almost the same. It is thought that the specimens did not degrade in entirety, but in a narrow area, due to xenon lamp irradiation and heating under the conditions employed in this study. Specimens degraded by the xenon lamp and heating were broken at the most damaged area by xenon light and heating, and the region of the SS curve prior to the break was superimposable on that of the pristine specimen.

The degree of degradation of the PET film due to irradiation with the xenon lamp and temperature was evaluated based on the maximum stress from the tensile test, since the effect of the chamber temperature on the elastic limit, yield point, and elastic modulus was unclear, as shown in Figure 5. The relationship between the temperature of the chamber and the maximum stress for the specimen irradiated with $222 \mathrm{~W} / \mathrm{m}^{2}$ for $8 \mathrm{~h}$ is compared with that of the unirradiated sample in Figure 6. The tensile strength of the irradiated specimen decreased linearly with increasing temperature, whereas the tensile strength of the unirradiated specimen decreased gradually with increasing temperature.

\subsection{Relationship between Tensile Strength and Light Intensity.} The results presented in Figure 6 illustrate that the tensile strength of the irradiated specimen declined with increasing chamber temperature. The effect of light intensity on the tensile strength was investigated for the specimens heated

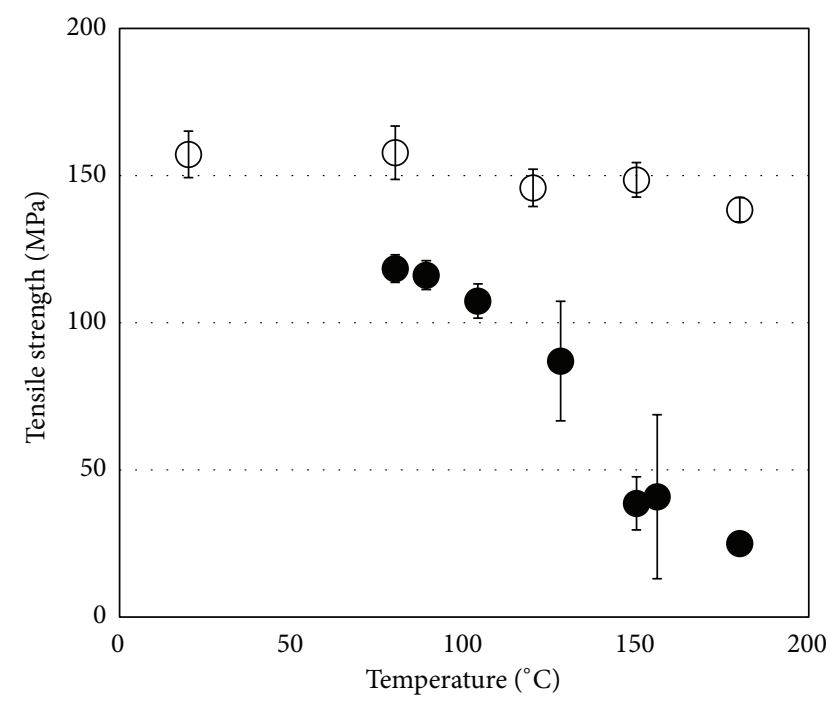

FIGURE 6: Relationship between tensile strength and temperature; - light intensity $222 \mathrm{~W} / \mathrm{m}^{2}$ for 8 hours and $\bigcirc$ only heating without irradiation for 8 hours.

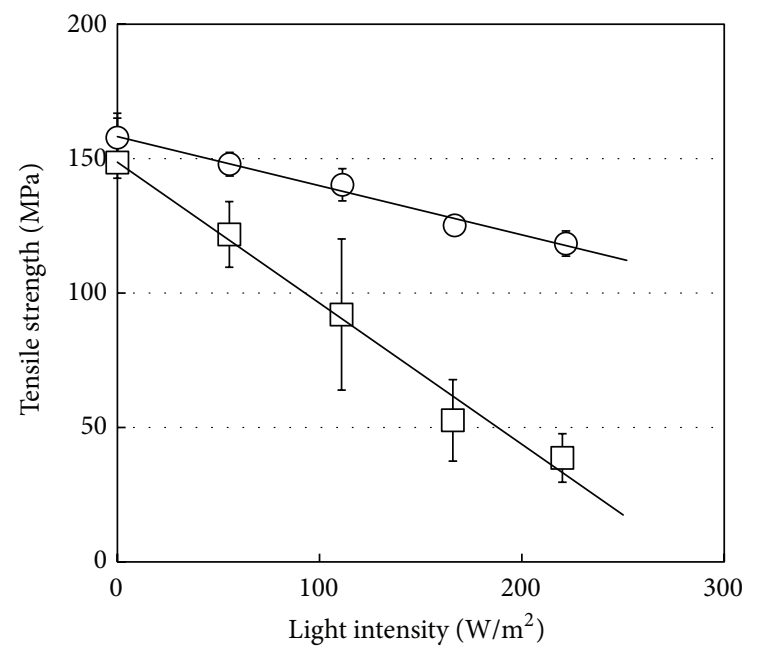

FIGURE 7: Relationship between tensile strength and light intensity; $O$ chamber temperature $80^{\circ} \mathrm{C}$ and $\square$ chamber temperature $150^{\circ} \mathrm{C}$.

at 80 and $150^{\circ} \mathrm{C}$ as shown in Figure 7. The tensile strength of these samples decreased with increasing light intensity, although the gradients of the relationship were different for both samples. The effect of irradiation time on the tensile strength was investigated for specimens irradiated with $222 \mathrm{~W} / \mathrm{m}^{2}$ at $150^{\circ} \mathrm{C}$ as indicated in Figure 8. The tensile strength decreased linearly with increasing irradiation time.

3.5. Model for Lifetime Prediction. Based on the results presented in Figures 7 and 8, it is assumed that the tensile strength decreases linearly with increasing light intensity or irradiation time. A model for prediction of the lifetime where the tensile strength of the PET film is $90 \%$ of that of the original PET film was developed for PET films degraded under various conditions. It is also assumed that degradation 


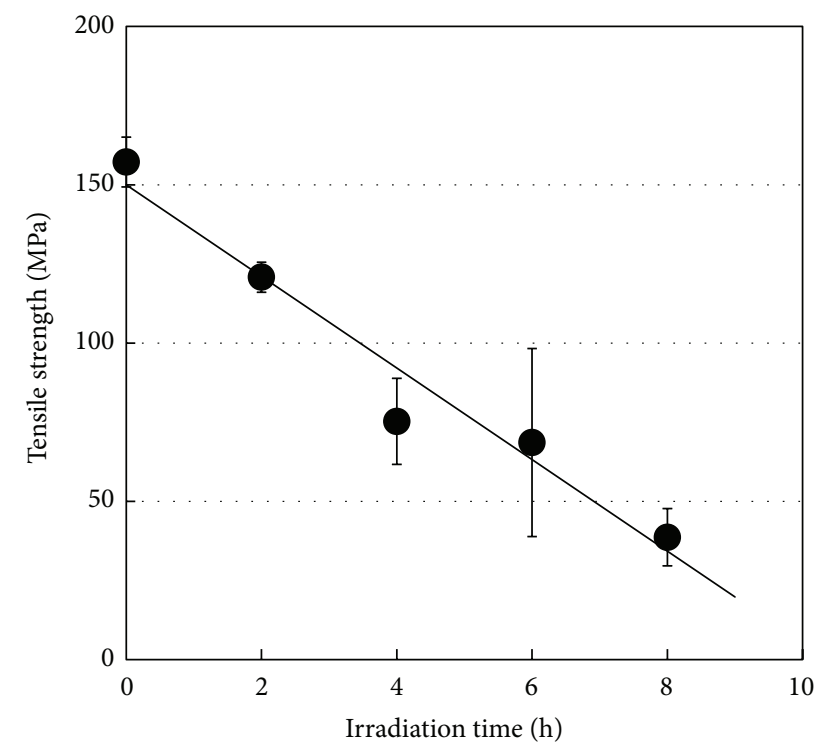

FIGURE 8: Relationship between tensile strength and irradiation time. Specimens with light intensity $222 \mathrm{~W} / \mathrm{m}^{2}$ at $150^{\circ} \mathrm{C}$.

by heating and light from a xenon lamp involves chemical reactions such as oxidation. That is, it is assumed that the natural logarithm of the time when the tensile strength reaches $90 \%$ of that of the initial strength is proportional to the reciprocal of the absolute temperature and is also proportional to the light intensity.

3.6. Eyring Model. The Eyring model is sometimes employed for lifetime prediction for plastic products. In the Eyring model, it is assumed that the exponential of one of the physical values (except for temperature) is proportional to the lifetime, independent of temperature. When light intensity is considered as the physical value apart from temperature, light intensity, and lifetime can be stated as

$$
\ln (t)=\frac{C_{1}}{T}+C_{2} I+C_{3},
$$

where $t$ is the lifetime, $T$ is the absolute temperature of the chamber, $I$ is the light intensity, and $C_{1}, C_{2}$, and $C_{3}$ are constants.

Lifetime is defined as the time when the tensile strength decreases to $90 \%$ of the initial strength for dumbbell shaped specimens of PET film. The values of the constants in formula (1) were derived by calculation from the lifetime data for the specimens degraded under various conditions by using the least squares method. Constants of $C_{1}, C_{2}$, and $C_{3}$ in formula (1) were calculated by the least squares method with the lifetime derived for the specimens degraded under various conditions. Calculation results applying fitted constants in formula (1) are shown in Figure 9. The symbols indicate the empirically derived lifetime and the lines show the results of calculations using formula (1). The reciprocal of the absolute temperature of the chamber is indicated on the horizontal axis and the vertical axis indicates the lifetime, expressed as a natural logarithm, where the tensile strength reaches $90 \%$ of

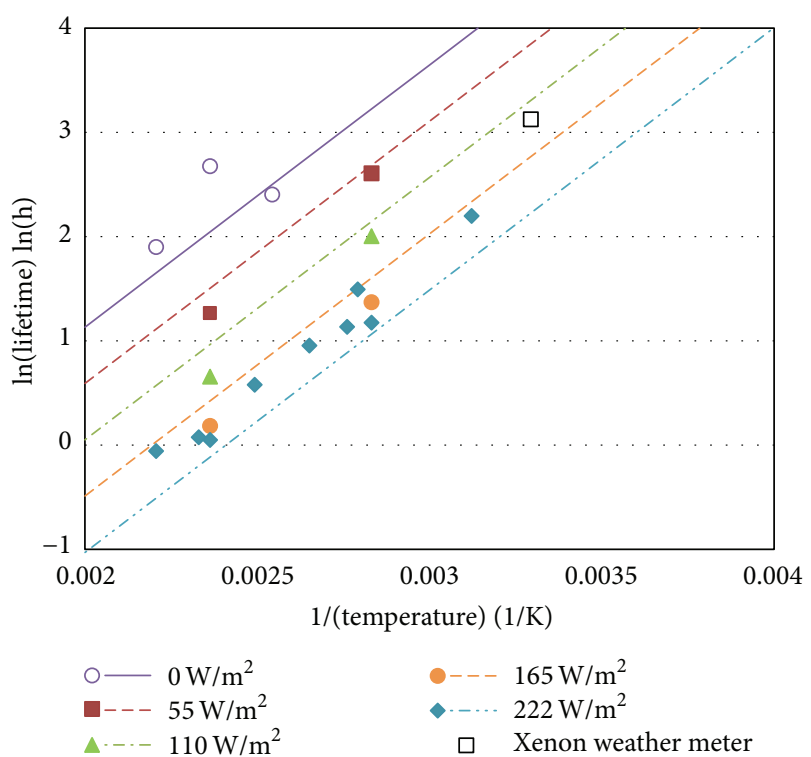

FIGURE 9: Prediction for lifetime at 90\% strength; Eyring model; symbols shown derived from experimental results; lines show calculated results.

the initial value. The times when the tensile strengths of the PET film specimens degraded under various conditions reach $90 \%$ of that of the original PET film specimen are calculated by linear extrapolation because the tensile strength decreases linearly with increasing light intensity or irradiation time, as shown in Figures 7 and 8. The results for the specimens degraded with different light intensities are indicated by different symbols and lines. The gradient of these lines agrees well with the trends of the empirical data. However, the empirical data are not coincident with the calculated lines. The experimental results for the specimens degraded with light intensities of 165 and $222 \mathrm{~W} / \mathrm{m}^{2}$, which are indicated by the symbols $\bullet$ and $\bullet$, are almost the same, as shown in Figure 9. One reason is that the coefficient for the light intensity is 0.0090032 , which is much smaller than 2516.2 for the absolute temperature. The effect of the light intensity on the lifetime (expressed as the natural logarithm) must be linear according to formula (1). The experimental results do not conform to this assumption. This indicates that the Eyring model is not suitable for prediction of the lifetime at which the strength of the PET film is $90 \%$ of the original one. The lifetime for $90 \%$ strength may be qualitatively predicted by the Eyring model given that the gradient of the calculated results for the lifetime agrees well with that of the experimental results. Further discussion and modification of the Eyring model are necessary for quantitative prediction of the lifetime.

3.7. Lifetime Prediction for Results from Weather Test Machine. Tensile tests were performed for dumbbell shaped PET specimens irradiated with $180 \mathrm{~W} / \mathrm{m}^{2}$ at $30.4^{\circ} \mathrm{C}$ using the xenon weather meter. Some of the experimental results are summarized in Table 3 . The lifetime of $90 \%$ strength $(132.4 \mathrm{MPa})$ of the specimens irradiated with $180 \mathrm{~W} / \mathrm{m}^{2}$ at 
TABLE 3: Tensile strength of specimens irradiated using xenon weather meter.

\begin{tabular}{lcc}
\hline $\begin{array}{l}\text { Irradiation time } \\
\mathrm{h}\end{array}$ & $\begin{array}{c}\text { Tensile strength } \\
\mathrm{MPa}\end{array}$ & $\begin{array}{c}\text { Standard deviation } \\
\mathrm{MPa}\end{array}$ \\
\hline 0 & 147.1 & 1.74 \\
24 & 126.8 & 3.86 \\
48 & 115.2 & 4.28 \\
\hline
\end{tabular}

$30.4^{\circ} \mathrm{C}$ is estimated to be $22.7 \mathrm{~h}$ from the data in Table 3. This value is plotted in Figure 9 as the experimental result at $30.4^{\circ} \mathrm{C}$ (indicated by the symbol $\square$ ). The multiple-correlation coefficient for the experimental data using the Eyring model was 0.958 . It is thought that prediction of the lifetime of $90 \%$ strength from the experiments can be expressed by the Eyring model, since the multiple-correlation coefficient of 0.958 is sufficiently close to 1.0 . The calculated lifetime for specimens irradiated with $180 \mathrm{~W} / \mathrm{m}^{2}$ at $30.4^{\circ} \mathrm{C}$ (Figure 9) is $15.9 \mathrm{~h}$. This is smaller than the experimental value of $22.7 \mathrm{~h}$. It is thought that the variation in the results arises from differences between the filter of the xenon lamp and the filter of the xenon weather meter. Specimens irradiated with the xenon lamp were found to be more extensively damaged than those irradiated with the xenon weather meter since the filter of the xenon lamp cuts UV light around 300 to $400 \mathrm{~nm}$ to a lesser extent than the filter of the xenon weather meter. The correlation between the effects of heat and light on PET degradation should be considered, although the effects of heat and light on the lifetime are assumed to be independent of each other in formula (1). Further investigation is necessary in order to clarify the effect of filters on the degradation of PET, although the xenon lamp without any filter is effective for acceleration of degradation by the xenon weather meter. Furthermore, investigation of the correlation between the effects of heat and light on PET degradation is also necessary for more accurate prediction of the lifetime of tensile strength.

\section{Conclusions}

A method for the degradation of PET films using a xenon lamp system with heating was developed to achieve greater accelerated aging of PET films relative to that achieved using the xenon weather meter. The tensile strength of PET films irradiated under various conditions using the xenon lamp at temperature ranging between 47 and $180^{\circ} \mathrm{C}$ was investigated. The SS curves obtained in tensile tests performed on the PET film were superimposable on those of the initial PET film. The area of the PET film degraded by the xenon lamp may be very small, and the number of degraded areas increased with increasing heating temperature, irradiation time, or light intensity. The lifetime at $90 \%$ of the original tensile strength was derived from the experimental results obtained by varying the heating temperature, irradiation time, and light intensity. The lifetime at $90 \%$ of the original tensile strength were simulated by using the Eyring model. The experimental lifetime trends could be qualitatively approximated by the Eyring model. The lifetime of $90 \%$ tensile strength empirically evaluated using the xenon weather meter was $22.7 \mathrm{~h}$, as opposed to the value of $15.9 \mathrm{~h}$ estimated using the Eyring model. The changes in the tensile strength observed with the use of the xenon weather meter can be accelerated by using a system combining the xenon lamp and a heater. It is necessary for improvement in lifetime prediction to collect more data of lifetime of samples on actual condition and measured lifetime on accelerated conditions. It is found that the degradation time needed for tensile strength of PET film irradiated by xenon light decreasing $90 \%$ of origin can be expressed using the Eyring model. It is necessary for the lifetime prediction of other properties except for tensile strength of PET films to collect much data of those properties of PET film under various conditions.

\section{Competing Interests}

The authors declare that they have no competing interests.

\section{References}

[1] P. Hülsmann, M. Heck, and M. Köhl, "Simulation of water vapor ingress into PV-modules under different climatic conditions," Journal of Materials, vol. 2013, Article ID 102691, 7 pages, 2013.

[2] N. Kim, H. Kang, K.-J. Hwang et al., "Study on the degradation of different types of backsheets used in PV module under accelerated conditions," Solar Energy Materials and Solar Cells, vol. 120, pp. 543-548, 2014.

[3] Z. Chen, B. Cotterell, W. Wang, E. Guenther, and S.-J. Chua, "A mechanical assessment of flexible optoelectronic devices," Thin Solid Films, vol. 394, no. 1-2, pp. 202-206, 2001.

[4] K. A. Sierros, N. J. Morris, K. Ramji, and D. R. Cairns, "Stresscorrosion cracking of indium tin oxide coated polyethylene terephthalate for flexible optoelectronic devices," Thin Solid Films, vol. 517, no. 8, pp. 2590-2595, 2009.

[5] K. A. Sierros, D. S. Hecht, D. A. Banerjee et al., "Durable transparent carbon nanotube films for flexible device components," Thin Solid Films, vol. 518, no. 23, pp. 6977-6983, 2010.

[6] F. Villain, J. Coudane, and M. Vert, "Thermal degradation of polyethylene terephthalate: study of polymer stabilization," Polymer Degradation and Stability, vol. 49, no. 3, pp. 393-397, 1995.

[7] F. Samperi, C. Puglisi, R. Alicata, and G. Montaudo, “Thermal degradation of poly(ethylene terephthalate) at the processing temperature," Polymer Degradation and Stability, vol. 83, no. 1, pp. 3-10, 2004.

[8] J. R. Campanelli, M. R. Kamal, and D. G. Cooper, "Kinetic study of the hydrolytic degradation of polyethylene terephthalate at high temperatures," Journal of Applied Polymer Science, vol. 48, no. 3, pp. 443-451, 1993.

[9] M. Day and D. M. Wiles, "Photochemical degradation of poly(ethylene terephthalate). I. Irradiation experiments with xenon and carbon arc," Journal of Applied Polymer Science, vol. 16, pp. 175-189, 1972.

[10] P. Blais, M. Day, and D. M. Wiles, "Photochemical degradation of poly (ethylene terephthalate). IV. Surface changes," Journal of Applied Polymer Science, vol. 17, no. 6, pp. 1895-1907, 1973.

[11] T. Grossetête, A. Rivaton, J. L. Gardette et al., "Photochemical degradation of poly(ethylene terephthalate)-modified copolymer," Polymer, vol. 41, no. 10, pp. 3541-3554, 2000. 
[12] K. R. Kirov and H. E. Assender, "Quantitative ATR-IR analysis of anisotropic polymer films: surface structure of commercial PET,' Macromolecules, vol. 38, no. 22, pp. 9258-9265, 2005.

[13] G. J. M. Fechine, R. M. Souto-Maior, and M. S. Rabello, "Structural changes during photodegradation of poly(ethylene terephthalate)," Journal of Materials Science, vol. 37, no. 23, pp. 49794984, 2002.

[14] G. J. M. Fechine, M. S. Rabello, R. M. Souto-Maior, and L. H. Catalani, "Surface characterization of photodegraded poly(ethylene terephthalate). The effect of ultraviolet absorbers," Polymer, vol. 45, no. 7, pp. 2303-2308, 2004.

[15] G. J. M. Fechine, P. A. Christensen, T. A. Egerton, and J. R. White, "Evaluation of poly(ethylene terephthalate) photostabilisation using FTIR spectrometry of evolved carbon dioxide," Polymer Degradation and Stability, vol. 94, no. 2, pp. 234-239, 2009.

[16] C. O. Lee, B. Chae, S. B. Kim, Y. M. Jung, and S. W. Lee, "Two-dimensional correlation analysis study of the photodegradation of poly(ethylene terephthalate) film," Vibrational Spectroscopy, vol. 60, pp. 142-145, 2012.

[17] H. Hagihara, A. Oishi, M. Funabashi, M. Kunioka, and H. Suda, "Free-volume hole size evaluated by positron annihilation lifetime spectroscopy in the amorphous part of poly(ethylene terephthalate) degraded by a weathering test," Polymer Degradation and Stability, vol. 110, pp. 389-394, 2014.

[18] L. Song, Q. Liu, and J. Li, "Effects of accelerated aging period of time at $180^{\circ} \mathrm{C}$ on tensile property of plain woven fabric/epoxy resin laminated composites," Applied Mechanics and Materials, vol. 182-183, pp. 76-79, 2012.

[19] M. Irie, T. Yamasaki, and Y. Okino, "Simple estimation method for life expectancy of optical disks using resampling statistical analysis," Japanese Journal of Applied Physics, vol. 47, no. 7, pp. 6035-6038, 2008.

[20] T. Koyanagi, M. Okano, T. Akatsu, Y. Fujii, and H. Nishimura, "The proposal of the new test method of rapid evaluation of hot water resistance about FRP,' Kouka Plastics, vol. 56, pp. 77-82, 2010.

[21] P. Malanowski, S. Huijser, R. A. T. M. van Benthem, L. G. J. van der Ven, J. Laven, and G. de With, "Photodegradation of poly(neopentyl isophthalate) part I: laboratory and outdoor conditions," Polymer Degradation and Stability, vol. 94, no. 11, pp. 2086-2094, 2009.

[22] Y. Azuma, H. Takeda, S. Watanabe, and H. Nakatani, "Outdoor and accelerated weathering tests for polypropylene and polypropylene/talc composites: a comparative study of their weathering behavior," Polymer Degradation and Stability, vol. 94, no. 12, pp. 2267-2274, 2009.

[23] Y. Lv, Y. Huang, J. Yang et al., "Outdoor and accelerated laboratory weathering of polypropylene: a comparison and correlation study," Polymer Degradation and Stability, vol. 112, pp. 145-159, 2015. 

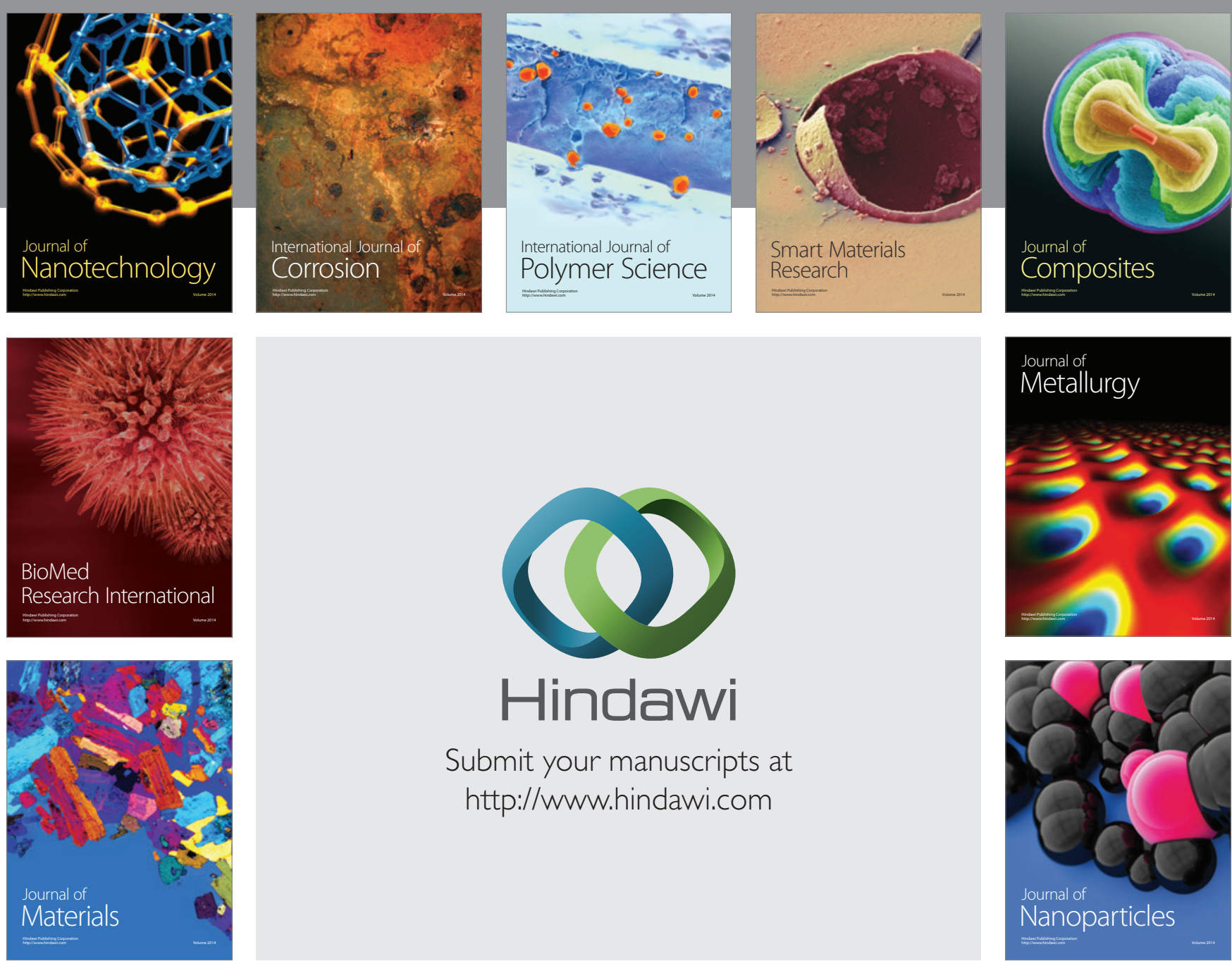

\section{Hindawi}

Submit your manuscripts at

http://www.hindawi.com

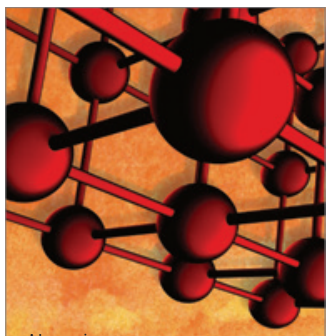

Materials Science and Engineering
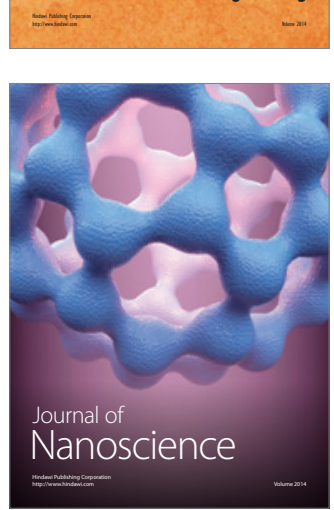
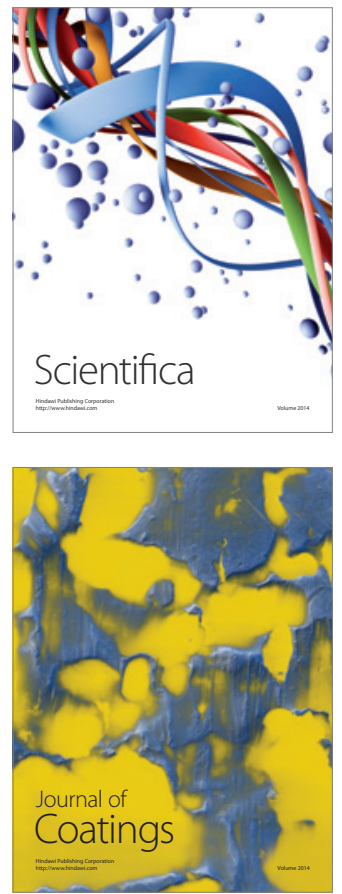
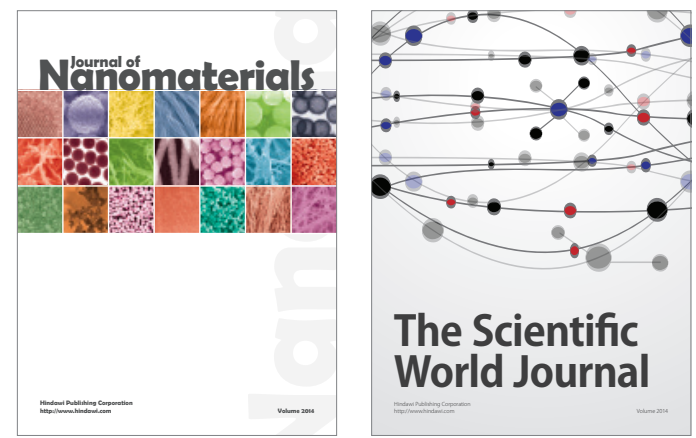

The Scientific World Journal
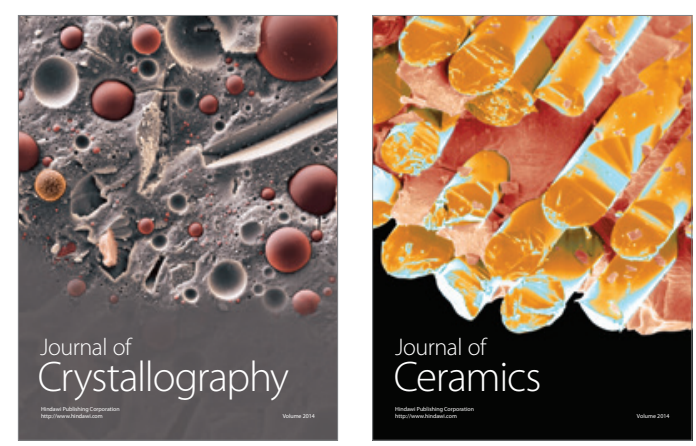
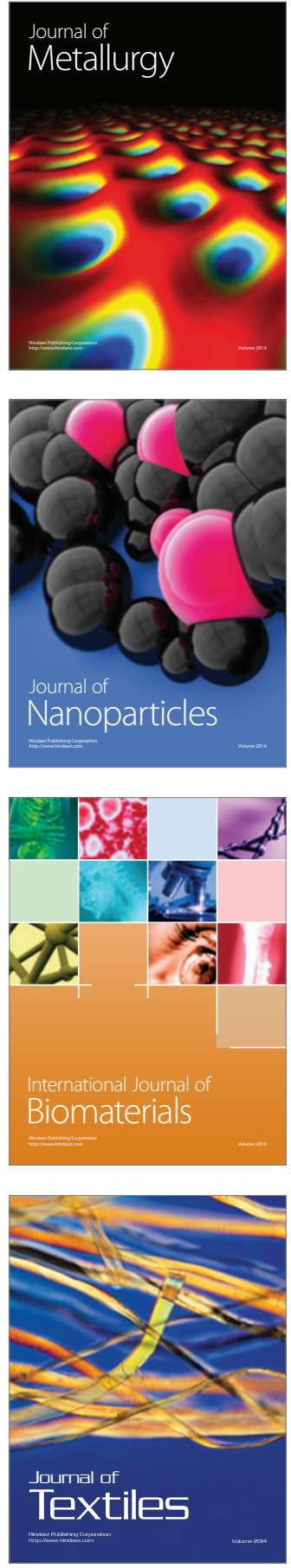